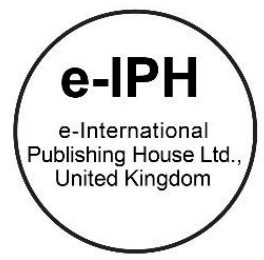

\title{
Disaster Resilience and Human Behavior: Hospital Buildings in Malaysia
}

\author{
Nor Malyana Samsuddin $1^{*}$, Roshana Takim ${ }^{2}$, Abdul Hadi Nawawi ${ }^{3}$ \\ ${ }^{1}$ Centre of Postgraduate Studies, \\ ${ }^{2}$ Centre of Construction Management Studies \\ Centre of Estate Management Studies, \\ Faculty of Architecture, Planning \& Surveying, Universiti Teknologi MARA, Shah Alam, Malaysia
}

\begin{abstract}
Hospitals are themselves vulnerable to numerous types of disasters and can get damaged risking the lives of human being. To a certain extent, despite of hard resilience (structural and non-structural), human behavior is one of the contributing factors affecting the hospital's capability in achieving disaster resilience. Hence, the objectives of the paper are twofold: to explore human weaknesses; and to investigate strategies for achieving disaster resilience for existing public hospitals. Qualitative research techniques were employed in the form of focus group approach. The findings revealed that six human weaknesses and five strategies have been asserted by the respondents as of utmost critical.
\end{abstract}

(C) 2016. The Authors. Published for AMER ABRA by e-International Publishing House, Ltd., UK. Peer-review under responsibility of AMER (Association of Malaysian Environment-Behaviour Researchers), ABRA (Association of Behavioural Researchers on Asians) and cE-Bs (Centre for Environment-Behaviour Studies, Faculty of Architecture, Planning \& Surveying, Universiti Teknologi MARA, Malaysia.

Keywords: Disaster Resilience; hard and soft resilience; hospital; human behaviour

\section{Introduction}

Disaster defines as event or occurrence that usually sudden and unexpected. Consequently, it intensely alters the beings, objects and localities under its influence. It results in loss of life, severe environmental damage, destruction or loss of material goods and disruption of normal patterns of life (Pan American Health Organization (PAHO), 2000). Hence, the concept of resilience is widely adopted across academic and policy debates as a way of reducing society's vulnerability to threats posed by natural and human induced disasters (Haigh \& Amaratunga, 2010a). According to Bruneau et al (2003), disaster resilience is the ability of social units (e.g. organizations, communities) to mitigate hazards, contain the effects of disasters when they occur, and carry out recovery activities in ways that minimize social disruptions. Similarly, United Nations International Strategy for Disaster Reduction (UNISDR) (2007) defines resilience as 'the ability of a system, community or society exposed to hazards to resist,

\footnotetext{
${ }^{*}$ Corresponding author. Tel.: +0-000-000-0000

E-mail address: malyanasamsuddin@gmail.com
} 
absorb, accommodate to and recover from the effects of a hazard in a timely and efficient manner through the preservation and restoration of its essential basic structures and functions.

Furthermore, disaster resilience emphasises the process and conditions within communities that enhance or reduce population's ability to resist, adapt to, and recover from a shock or perturbation within the shortest possible time and with little or no outside assistance. Disaster resilience, in this way, is often synonymous with the notions of 'bouncing back' or 'jumping back' (Ranjan \& Abenayake, 2014). A system is usually designed to behave in a certain way under normal circumstances. When disturbed from equilibrium by a disruptive event, the performance of the system will deviate from its design level. The resilience of the system is its ability to reduce both magnitude and duration of the deviation as efficiently as possible to its usual targeted system performance levels (Proag, 2014).

The concepts of resilience take two broad forms of strategies, namely hard resilience and soft resilience (Proag, 2014). Moench (2009) defines hard resilience as the direct strength of structures or institutions when placed under pressure, as such increasing its resilience through specific strengthening measures could reduce its probability of collapse. On the contrary, soft resilience is the ability of systems to absorb and recover from the impact of disruptive events without fundamental changes in function or structure. It could be achieved through the flexibility and adaptive capacity of the system as a whole, rather than strengthening structures or institutions in relation to specific stresses, as in the hard resilience approach. Fiksel (2003) and Rose \& Liao (2005) emphasize on three types of capacities which are: absorptive capacity (the ability of the system to absorb the disruptive event); adaptive capacity (ability to adapt the event); and restorative capacity (the ability of the system to recover).

Bruneau et al., (2003) and Ranjan \& Abenayake (2014) suggest that hospital facilities as one of the attributes of disaster resilience community. It corroborates with Proag (2014), which highlights that public health and healthcare are amongst the infrastructure assets that should be pondered upon as resilient. Pursuing this further, disaster resilience hospital is the hospital's capability to resist, absorb, respond to the shock of disasters while still retaining their most essential functionality (e.g., prehospital care, emergency medical treatment, critical care, decontamination and isolation), then recover to its original state or a new adaptive state (Albanese et al., 2008; Bruneau et al., 2003; Cimellaro, Reinhorn, \& Bruneau, 2010).

\section{Disaster and Human Behaviour: Public Hospitals in Malaysia}

O' Keefe et al. (1976) argue that disasters were neither an 'act of god' nor an 'act of science' but consequences of vulnerabilities. As such, according to Voogd (2004) the disaster impact has a direct or indirect link with the actions of human beings. As a result, it could be reduced by implementing an effective disaster management. In addition, Neil (1986) identifies disasters as social events created by human behaviors where the tendency is dependent on the relationship between humans and their use of the physical and social world. For instance, Quarantelli \& Perry (2005) argue that disasters stem from the social system and not necessarily from the event itself. It corroborates with Haigh \& Amaratunga (2010b), by which many of the other disasters affecting populations in the last decade are unquestionably of human origin. In addition, technical disasters also have human origins, either caused by accident, negligence or incompetence.

It is proven in Malaysia that the impacts of various types of disasters (i.e. flood, fire, ceiling collapses, unhygienic hospital conditions, stolen equipment, and technical glitches) are affecting negatively towards public hospitals' resilience. To a certain extent, it is believed that human behaviours are one of the contributing factors affecting the hospital's capability for achieving disaster resilience. These human behaviours could be in the form of different disaster risk perceptions, and human weaknesses that result to incapability in establishing coping strategies for hospital's organisation. Weakness is defined as the state or quality of being weak; particularly in human behaviour context weakness is a deficiency or failing in a person's character (http://www.collinsdictionary.com, 2015). Consequently, Seguí-Mas \& Izquierdo (2009), highlight that behaviour contributes to the performance of tasks inherent to one's activity and responds to the individual's experience and situational stimulus in certain periods of time. Hence, it could be inferred that human weaknesses in terms of human behaviours could result in individual's performance in coping towards disasters.

According to Mohammad-Idrose (2014), during the flood in 1995 and 2010 the emergency department of Hospital Kuala Lumpur and Hospital Kangar was flooded and unable to continue functioning. Similarly, the patients of Hospital Alor Star have to be evacuated to other hospitals due to water supply shortage and risk of electric supply being cut. Of late, during the flood occurrences, two public hospitals (Hospital Raja Perempuan Zainab II and Kuala Krai Hospital) were badly affected. It is due to the fact that the flood waters had entered the premises and cause damages to few wards and equipment of Hospital Raja Perempuan Zainab II (Yahaya, 2015). On the other hand, for Kuala Krai Hospital, the hospital has been running on a generator after electricity supply was cut off. It has caused the hospital to total darkness and the patients in the intensive care unit (ICU) 
and critical care unit (CCU) were breathing on the machine running on battery power. To a certain extent, an anesthesiologist has had to intubate a baby in the dark to save the child's life after the generator ran out of fuel (Abdullah, 2014).

Several incidents involving fire at Putrajaya Hospital (2009), Sarawak General Hospital (2013), Sungai Buloh Hospital (2014), Kuala Lumpur Hospital (2014), and Sarawak General Hospital (2014) were believed caused by several factors such as lightning, unmaintained underground cables, short circuits and human negligence (Subramaniam, 2014b, 2014c; Susil, 2013; Yusof, 2014). Likewise at Serdang Hospital, the ceiling has collapsed seventh time since 2011 and has caused to several injuries (Subramaniam, 2013). Similarly, at Raja Permaisuri Bainun Hospital (2012), the ceiling has collapsed due to the fact that it was unable to support the weight of PVC pipe containing telephone and ICT cables. It is believed that the incidents happened due to poor workmanship by the contractors during the construction stage (Hang-Soon, 2012).

Apart from that, five public hospitals were in unhygienic conditions for seven days such as bins were overflowing, toilet and wards were not cleaned and nauseating stench from the toilets was disgusting. According to Subramaniam (2014a), the unhygienic hospital conditions were caused by the insufficient manpower from the facilities contractor. Based on the National Audit Department Malaysia (2013) in 2012, nearly RM1.5 million medicines and equipment were stolen from public hospitals. It includes loss of 97 assets comprising of air-conditioning compressors, syringe, pumps, physiologic monitoring system and pulse oxymeters.

Hence, it can be deduced that human behaviour in the form of weaknesses (i.e. negligence and lack of integrity) among the hospital stakeholders (e.g. clinicians, health service, and facility managers) could results to various types of disasters that affecting the hospital's resilience. Carthey, Chandra, \& Loosemore, (2008) highlight that it is essential to integrate responses with existing asset and disaster management frameworks and to also involve clinicians, health service and facility managers in decision-making processes to ensure more effective community responses and greater pressure for the development of adaptive capacity for healthcare infrastructure. In regards of these notions, Achour \& Price (2010) highlight the need to review current resilient strategies. It is supported by Achour et al.(2014), developing the right strategy could be the most significant step towards the resilience of healthcare facilities. Therefore, the objectives of the paper are twofold: to explore human weaknesses; and to investigate strategies for achieving disaster resilience for existing public hospitals.

\section{Research Methodology}

Qualitative research techniques were employed in the form of focus group approach among public agencies involving MERCY Malaysia; hospital emergency physicians; and academicians. The purposes of focus group approach are: to explore human weaknesses and to investigate strategies for achieving disaster resilience for existing public hospitals. The approach was conducted in the form of brainstorming session which the session was taped and transcribed verbatim for content analysis. The group involved has been assured to have a comfortable and private setting with the professional moderator. They are inquired with a question each that may generate the participant's involvement in creating an effective and interesting environment. Meanwhile the facilitator is accountable to write up the input and data by observation along with the discussion. The data then were used to clarify and analyze if it was required for the study, to formulate the transcripts. The material has been provided for each of the participants that are applicable and related to the study (Che-Mohd-Hashim \& Musa, 2014).

According to Cojocaru (2003), focus group technique is a qualitative data collection concerning views, needs, perceptions and motivations of participants. Through focus group technique the researchers can collect data, identify the needs and expectations, the way of thinking and way of expressing. Bostan (2015) defines focus-group as a research technique in which data collection is made through support group interaction on a topic determined by the researcher. Participants discuss in a relaxing way, share the ideas, comments and influence each other; communication is normal, natural, with a high degree of fidelity to the subject discussed.

Morse (1994) recommends a minimum of six interviews for phenomenological studies. It is supported by Guest, Bunce, \& Johnson (2006) by which it is suggested that a sample of six interviews could have been sufficient for various forms of data collection methods, such as focus groups, observation, or historical analysis. Six respondents have been selected for the purpose of this research. Hence, it can be inferred that the number of respondents involved is acceptable. The six potential respondents were selected based on their experience in disaster management area, particularly in the hospital. In addition, the emergency physicians represent their public hospitals' organizations. Therefore, it could be deduced that the data collected for the purpose of this paper are reliable. Table 1 provides the sample of the six respondents that were involved in the focus group approach. 
Table 1. Respondents' Background

\begin{tabular}{llll}
\hline & Organisation & Designation & Years of experience \\
\hline R1 & MERCY Malaysia & Head of Technical Team & 25 \\
R2 & Public Hospital & Emergency Physician & 6 \\
R3 & Public Hospital & Emergency Physician & 5 \\
R4 & Public Hospital & Emergency Physician & 3 \\
R5 & Faculty of Health Science, UiTM & Academician & 31 \\
R6 & Faculty of Civil Engineering, UiTM & Academician & 21 \\
\hline
\end{tabular}

\section{Findings and Results}

\subsection{Human weaknesses - hindering the capability of existing public hospitals to achieve disaster resilience}

Table 2 shows six human weaknesses that are hindering the capability of existing public hospitals to achieve disaster resilience. These are: absence of clear guidelines / assessment tool / framework; lack of hospitals' organisation awareness on international guidelines / assessment tool / framework; limited spaces and limited bed capacity; high intensity of patient; established computerized systems are too rigid and varies legal procedures designed by policy makers to be endured.

Table 2. Human weaknesses hindering the capability of existing public hospitals to achieve disaster resilience

\begin{tabular}{ll}
\hline Respondent & Respondents' statements \\
\hline R2, R3 & Absence of clear guidelines / assessment tool / framework established for disaster resilient hospital \\
R1,R5, R6 & Lack of hospitals' organisation awareness on international guidelines / assessment tool / framework \\
R3 & Established computerized systems are too rigid \\
R1 & Limited spaces for modified critical care and treatment space \\
R4 & Limited bed capacity and high intensity of patient in the future would cause the hospital unable to \\
& function accordingly \\
R5 & Varies legal procedures designed by policy makers to be endured \\
\hline
\end{tabular}

Based on the results, R2 and R3 agreed that the hospitals' organisation has not yet established a clear guidelines lassessment tool/ framework for disaster resilient hospital. It particularly implies for the trauma center and decontamination unit. In addition, the disaster simulation were done only for ISO purposes, none massive fire drill conducted and all parties were not being integrated during the safety or risk assessment. It corroborates with Malalgoda et al. (2014), empirical evidence revealed that the existing regulatory frameworks on planning, design and construction does not adequately look into disaster impacts and resilience as one of the challenges in achieving disaster resilience built environment. R3 postulated that the guidelines, assessment tool or framework should be implemented as a holistic approach, not solely involved emergency department.

Apart from that, R1, R5 and R6 emphasized that lack of hospitals' organisation awareness on international guidelines I assessment tool / framework could hinder the capability of existing public hospitals to achieve disaster resilience. At presence, R6 highlighted that none of the international guidelines, particularly seismic code of practice being referred to the hospital's construction. As a result, R1 recommended that guidelines by National Society for Earthquake Technology (NSET) Nepal could ponder upon into the process of designing and construction of public hospitals in Malaysia. In addition R5 suggested that the Hyogo Framework for Action 2005 - 2015 should act as the baseline for all the guidelines, assessment tool and framework.

Furthermore, R3 indicated that despite few public hospitals have implemented computerized information system; the system itself is too rigid and unable to keep pace with the high intensity of patients. R3 recommended that the computerized system should be more flexible. It in-line with Ismail et al., (2010) that few recommendations such as regular upgrading of hardware and software on needed basis to keep up with the pace of technology advancement and increasing number of patients and development of hospital information system to be flexible as to readily accommodate changes and advances of technology. 
Moreover, R1asserted that in few public hospitals, there are limited spaces that could be modified for mass casualty critical illness and injury. It is in-line with Hotchkin \& Rubinson (2008) that expansion of complex, everyday critical care for hundreds to thousands of people is immensely difficult for nearly all communities because of limited reserve critical care medical equipment, specialized staff, and traditional intensive care unit (ICU) treatment space. It is suggested that when traditional critical care capacity is full, additional critically ill patients should receive care in non-ICU hospital rooms that are concentrated on specific hospital wards or floors. The space should be able to provide service for measuring oxygen saturation, temperature, blood pressure and urine output for the victims in emergency mass critical care conditions. However, if the hospitals' organisations are unable to provide these spaces, it could result in the hospitals' service breakdown.

On the other hand, R4 points out that limited bed capacity and high intensity of patient in the future would cause the hospital unable to function accordingly. It is supported by National Association of Public Hospitals and Health System (NAPH) (2007), which the ability to manage daily surge, adequate amounts of space and staffing directly affects how hospitals will handle patient surges during an emergency. Proudlove et al., (2003) propose bed management as one of the strategies to be incorporated within the hospitals' organisations. Bed management, should be part of operational capacity management that plays a vital role in establishing and maintaining a stock of empty beds during disaster occurrences.

In addition, R5 stressed that vary legal procedures designed by policy makers could result to incapability of existing public hospitals to achieve disaster resilience. The growing bureaucracy in the hospitals' organisations presents a serious threat to physicians' ability to provide quality patient care. To recapitulate, these human weaknesses mentioned earlier, have been asserted by all the respondents as the utmost critical factors that could hinder the capability of existing public hospitals to achieve disaster resilience.

Given the above, without any control on these six human weaknesses (i.e. lack of guidelines / assessment tool / framework, lack of awareness, computerized system too rigid, limited spaces, limited bed capacity, high intensity of patients and messy legal procedures) it could lead to a severe impact to hospital's infrastructure and organisation. Hence, strategies to control human weaknesses mentioned earlier should be established.

\subsection{Strategies- for achieving disaster resilience for existing public hospitals}

- Combination of Hard Resilience (Structural \& Non-Structural) and Soft Resilience (Functional)

Table 3 shows the combination of hard and soft resilience strategies for existing public hospitals. Both hard and soft resilience strategies are classified into three components such as: structural, non-structural and functional. Structural and nonstructural are considered to be hard resilience; meanwhile functional is regarded as soft resilience. The findings revealed that the components mentioned earlier (i.e., structural; non-structural; and functional) have been asserted as critical components for hard and soft resilience strategies to be implemented by public hospitals in Malaysia.

Table 3. Combination of Hard Resilience (Structural \& Non-Structural) and Soft Resilience (Functional)

\section{Combination of Hard Resilience (Structural \& Non-Structural) and Soft Resilience (Functional)}

R1 The disaster resilience hospital should have the capability to protect their structural and non-structural element through its functional capacity such as emergency planning system (i.e. nursing call system) and community management (i.e. staff and patient)

R2 Disaster resilience hospital is the hospital's capability to respond from any disasters by incorporating its functional element via emergency management system.

R3 Disaster resilience hospital integrates the management of its physical aspect, non-structural, hospital emergency system and the human resources in order for the hospital to continue functioning during disaster occurrences.

R5 Disaster resilience hospital is the ability to minimise any disruption in hospital operation during the occurrences of any types of disasters and it can be achieved by providing contingency planning and training to the hospital organisation.

R6 Disaster resilience hospital is the ability of the organization to contain the effects of disasters through strengthening its structure particularly in seismic code of practice

Source: (Samsuddin et al., 2015) 
Based on the results, R1, R3 and R6 agreed that disaster resilience hospital should equip its structure in order to resist and absorb the shock of disasters. The structure should focus on the components such as: type of design; structures; construction materials; and prior events affecting hospital safety.

Apart from that, both R1 and R3 recommended that non-structural components (i.e., architectural elements; lifeline facilities; medical and laboratory equipment; and security of equipment and supplies) are worth to be considered as hard resilience strategies for the purpose to absorb, adapting and recovering to disasters.

Moreover, R1, R2, R3 and R4 asserted that functional components (i.e., site and accessibility; internal circulation and interoperability; equipment and supplies; emergency standard operating procedures and guidelines; logistic systems and utilities; security and alarm; transportation and communication systems; human resources and monitoring and evaluation) are another components to be incorporated as resilience strategies (soft resilience) for existing public hospitals.

- In-depth soft resilience strategies

In relation to this paper with regards to human behavior, Table 4 shows in-depth findings for five soft resilience strategies (functional components). The findings revealed that the five strategies have been asserted by the respondents as of utmost critical which are: establishing disaster hospital policy / assessment tool / framework; continuous assessment; comprehensive planning; awareness through table top exercise; and transparency. Unanimously, the respondents agreed that the recommended strategies were seen as the essential element in soft resilience. Apart from soft resilience, hard resilience (i.e., strengthening work, underpinning, major refurbishment) are difficult to improve given of the high uncertainty of natural disasters. Hence, it could be deduced that the soft resilience strategies are worth to be considered. In addition, those strategies will be extensively classified to absorptive, adaptive and restorative capacity.

Table 4. In-depth soft resilience strategies for existing public hospitals

\begin{tabular}{|c|c|c|c|c|}
\hline \multirow[t]{2}{*}{ Respondent } & \multirow{2}{*}{ Respondents' statements } & \multicolumn{3}{|c|}{ Soft resilience } \\
\hline & & $\mathrm{AB}$ & $\mathrm{AD}$ & $\mathrm{RT}$ \\
\hline R5 & Establish policy, assessment tool or framework and should be endorsed by top management & $\sqrt{ }$ & $\sqrt{ }$ & $\sqrt{ }$ \\
\hline $\mathrm{R} 1$ & Continuous assessment to ensure the sustainability of disaster resilience & $\sqrt{ }$ & $\sqrt{ }$ & \\
\hline R6 & $\begin{array}{l}\text { Comprehensive planning involving all stakeholders including the end users. Backup storage } \\
\text { room should be planned to cater for disaster in the future }\end{array}$ & $\sqrt{ }$ & $\sqrt{ }$ & $\sqrt{ }$ \\
\hline R2 & Awareness through table-top exercise & $\sqrt{ }$ & & $\sqrt{ }$ \\
\hline $\mathrm{R} 1, \mathrm{R} 3$ & Transparency with the budget in providing better hospital, education and training & $\sqrt{ }$ & & \\
\hline
\end{tabular}

${ }^{*} A B$ - Absorptive Capacity; AD - Adaptive Capacity; RT - Restorative Capacity

Based on the results, R5 affirmed that the hospitals' top management should establish and endorse the policy, assessment tool or framework related to disaster resilient hospital. It is due to the fact that, it could serve as guidelines to the hospitals' stakeholders in achieving disaster resilient hospital. According to Zhong et al., (2014) the framework can be regarded as a checklist to evaluate key indicators of hospital vulnerability and to identify priority practices that could prepare the facilities better for future disasters. The guidelines, assessment tool or framework should encompass for mitigation, preparedness, response and recovery in order to absorb, easily adapt to the disaster and able to recover quickly. Hence, it implies that this strategy will enhance the hospital's absorptive, adaptive and restorative capacity.

Furthermore, R1 stressed that the continuous safety assessment of the hospitals could ensure the sustainability of disaster resilience hospital. This implies that, it is essential for the hospitals' stakeholders to assess the facilities continuously, in order to address the gaps in emergency management competencies (Rockenschaub \& Harbou, 2013). According to Smith et al, (2010) the assessment could be accomplished through the use of checklist by which the criteria categories used are: current disaster planning strategy, bed capacity, surgical capacity, blood transfusion resources, supplies of medicines and equipment, staff availability, staff training, communication facilities, transport availability and disease surveillance and control. In relation to that, continuous improvement could be established for strengthening absorptive capacity and adaptive capacity.

Apart from that, R6 asserted that comprehensive planning should be involving all stakeholders including the end users. In addition, $\mathrm{R} 6$ pointed out that the utmost critical component in the plan is the allocation of backup storage room for future disaster. 
The backup storage room will be equipped with the alternative supply of medical and surgical equipment, alternative fuel and generator. The purpose of allocating these alternatives supplies is for easily adapting to disaster in any case the available supplies are non-functioning and limited. It is supported by Phalkey et al (2012), which simple steps like developing facilityspecific preparedness plans which detail out standard operating procedures during disasters and identify clear lines of command for hospitals' facilities will strengthen the response to future disasters. In addition, each hospital facility should maintain contingency funds for emergency response and recovery along with local vendor agreements to ensure stock supplies during disasters. It could be deduced that, those strategies are integrated for the purpose of absorbing, adapting and restoring to the disasters.

On the other hand, R2 uphold that awareness should be created among the hospitals' organisation through tabletop exercise. Peterson \& Perry (1999) assure that successful exercises can enhance perceptions of teamwork, training adequacy, response network effectiveness, job risk, and equipment adequacy for the hospitals' organisations. Table-top and field exercises are efficient tools to ensure readiness and assess response capabilities. In addition, a tabletop exercise could be in the form of disaster recovery (DR) exercise that provides a practical checklist of procedures to follow during a disaster. It implies that, those exercises provide better absorptive and restorative capacity.

Based on Malalgoda et al. (2014) corruption and unlawful activities are quite common in the construction sector and as a result planning regulations and approval systems are sometimes overruled due to various reasons such as political pressure and bribery. Ad hoc construction and land use decisions further aggravate the situation and adversely affect the efforts of building a safer built environment. In relation to that, R1 and R3 alleged that transparency as one of the practical measures taken to curtail corruption. It is in-line with Takim et al (2013) by which transparency is an essential precondition for containing corruption. It is suggested that any method that helps ensure quality, timely delivery at reasonable cost is a transparency strategy. Hence, by establishing a quality hospital in terms of its structure, the structure itself could resist and absorb from any shocks of disasters.

Given the above, implementing these five strategies (i.e. establishing disaster hospital policy / assessment tool / framework; continuous assessment; comprehensive planning; awareness through table top exercise; and transparency) it could enhance the ability of the hospital to resist, absorb and respond to the shock of disasters while still retaining their critical functions, then recover to its original state or a new adaptive state.

\section{Conclusion}

This paper has presented the findings on human weaknesses that hindering the capability of existing hospitals to achieve disaster resilience and strategies to combat those weaknesses, Six human weaknesses (i.e. absence of clear guidelines / assessment tool / framework; lack of hospitals' organisation awareness on international guidelines / assessment tool / framework; limited spaces and limited bed capacity; high intensity of patient; established computerized systems are too rigid and varies legal procedures designed by policy makers to be endured) have been addressed as utmost critical weaknesses that affecting the existing public hospitals in achieving disaster resilient.

In relation to that, the respondents pointed out that resilience strategy for existing public hospitals is in the form of hard resilience (structural and non-structural) and soft resilience (functional). Consequently, in relation to this paper with regards to human behavior, in-depth findings for five soft resilience strategies (i.e. establishing disaster hospital policy / assessment tool / framework; continuous assessment; comprehensive planning; awareness through table top exercise; and transparency) have been identified as vital components in achieving disaster resilience for existing public hospitals. Those hard and soft resilience strategies will result in enhancing the hospitals' absorptive, adaptive and restorative capacity. Hence, the paper makes an original contribution to the broader area of hospital disaster management. The results of the study could serve as guidelines for the future development of hospital buildings. In addition, those strategies could help in disaster response and recovery to the hospital's infrastructure and organisation.

The research presented in this paper is part of an ongoing Ph.D research study at the Faculty of Architecture, Planning and Surveying, UiTM to develop a framework of disaster resilience for public hospitals in Malaysia. The result of the study justifies the research gaps which establishing framework is needed to enhance disaster resilience for public hospitals in Malaysia. Hence, the research presented in this paper is limited to validating the research needs in disaster management area, particularly for public hospital buildings. 


\section{References}

Abdullah, A. (2014). Kuala Krai Hospital in darkness. Astro Awani.

Achour, N., Miyajima, M., Pascale, F., \& Price, A. D. F. (2014). Hospital resilience to natural hazards: classification and performance of utilities. Disaster Prevention and Management, 23(1), 40-52. doi:10.1108/DPM-03-2013-0057

Achour, N., \& Price, A. D. F. (2010). Resilience strategies of healthcare facilities: present and future. International Journal of Disaster Resilience in the Built Environment, 1(3), 264-276. doi:10.1108/17595901011080869

Albanese, J., Birnbaum, M., Cannon, C., Cappiello, J., Chapman, E., Paturas, J., \& Smith, S. (2008). Fostering disaster resilient communities across the globe through the incorporation of safe and resilient hospitals for community-integrated disaster responses. Prehospital and Disaster Medicine, 23(5), 385-90. Retrieved from http://www.ncbi.nlm.nih.gov/pubmed/19189606

Bostan, C.-G. (2015). Focus-group Research on Modern Techniques and Multimedia Tools Implementation in Teaching Practice. Procedia - Social and Behavioral Sciences, 180, 1444-1450. doi:10.1016/j.sbspro.2015.02.291

Bruneau, M., Chang, S. E., Eguchi, R. T., Lee, G. C., O’Rourke, T. D., Reinhorn, A. M., ... von Winterfeldt, D. (2003). A Framework to Quantitatively Assess and Enhance the Seismic Resilience of Communities. Earthquake Spectra, 19(4), 733-752. doi:10.1193/1.1623497

Carthey, J., Chandra, V., \& Loosemore, M. (2008). Assessing the Adaptive Capacity of Hospital Facilities to Cope with Climate-Related Extreme Weather Events : A Risk Management Approach. In Procs 24th Annual ARCOM Conference, 1-3 September 2008, Cardiff, UK, Association of Researchers in Construction Management (pp. 1145-1154).

Che-Mohd-Hashim, J. A., \& Musa, R. (2014). Factors Influencing Attitude towards Halal Cosmetic among Young Adult Urban Muslim Women: A Focus Group Analysis. Procedia - Social and Behavioral Sciences, 130, 129-134. doi:10.1016/j.sbspro.2014.04.016

Cimellaro, G. P., Reinhorn, A. M., \& Bruneau, M. (2010). Seismic resilience of a hospital system. Structure and Infrastructure Engineering, 6(1-2), 127-144. doi:10.1080/15732470802663847

Cojocaru, D. (2003). Focus group - social research technique. Journal of Research and Social Intervention, 3.

Fiksel, J. (2003). Designing Resilient, Sustainable Systems. Environmental Science and Technology, 37(23), 5330-5339.

Guest, G., Bunce, A., \& Johnson, L. (2006). How Many Interviews Are Enough?: An Experiment with Data Saturation and Variability. Field Methods, 18(1), 5982. doi:10.1177/1525822X05279903

Haigh, R., \& Amaratunga, D. (2010a). An integrative review of the built environment discipline 's role in the development of society 's resilience to disasters, 1(1), 11-24. doi:10.1108/17595901011026454

Haigh, R., \& Amaratunga, D. (2010b). An integrative review of the built environment discipline's role in the development of society's resilience to disasters. International Journal of Disaster Resilience in the Built Environment, 1(1), 11-24.

Hang-Soon, M. (2012). Ipoh Hospital ceiling collapses. In Press Conference Wednesday, October 31, 2012, Ipoh. Astro Awani.

Hotchkin, D. L., \& Rubinson, L. (2008). Modified Critical Care and Treatment Space Considerations for Mass Casualty Critical IIIness and Injury. Respiratory Care, 53(1), 67-77.

http://www.collinsdictionary.com. (2015). Collins English Dictionary. Retrieved September 28, 2015, from http://www.collinsdictionary.com

Ismail, A., Jamil, A. T., Rahman, A. F. A., Madihah Jannatul, Bakar, A., Natrah, M. S., \& Hussain, S. (2010). The Implementation Of Hospital Information System ( HIS ) In Tertiary Hospitals In Malaysia : A Qualitative Study. Malaysian Journal of Public Health, 10(2), 16-24.

Malalgoda, C., Amaratunga, D., \& Haigh, R. (2014). Challenges in Creating a Disaster Resilient Built Environment. Procedia Economics and Finance, 18, 736744. doi:10.1016/S2212-5671(14)00997-6

Moench, M. (2009). Adapting to Climate Change and the Risks associated with Other Natural Hazards: Methods for Moving from Concepts to Action. The Earthscan Reader on Adaptation to Climate Change, 249-280.

Mohammad-Idrose, A. (2014). Disaster Resilient Hospital. In Keynote Speaker at Disaster and Business Continuity Management Seminar, June, 24 2014, OIA Multipurpose Hall, UiTM Shah Alam.

Morse, J. (1994). Designing funded qualitative research. In Handbook for qualitative research (pp. 220-35).

National Association of Public Hospitals and Health System (NAPH). (2007). Hospital Staffing and Surge Capacity During a Disaster Event. Research Brief.

National Audit Department Malaysia. (2013). Auditor General's Report Federal 2013.

Neil, B. (1986). Developing an understanding of disaster. Journal of Sociology, 22(2), 254-271.

O' Keefe, P., Westgate, K., \& Wisner, B. (1976). Taking the naturalness out of natural disasters. Nature, 260(1), 566-567.

Pan American Health Organization (PAHO). (2000). Principles of Disaster Mitigation in Health Facilities.

Peterson, D. M., \& Perry, R. W. (1999). The impacts of disaster exercises on participants. Disaster Prevention and Management, 8(4), $241-255$. doi:10.1108/09653569910283879

Phalkey, R., Dash, S. R., Mukhopadhyay, A., Runge-Ranzinger, S., \& Marx, M. (2012). Prepared to react? Assessing the functional capacity of the primary health care system in rural Orissa, India to respond to the devastating flood of September 2008. Global Health Action, 5, 1-10. doi:10.3402/gha.v5i0.10964

Proag, V. (2014). Assessing and Measuring Resilience. Procedia Economics and Finance, 18, 222-229. doi:10.1016/S2212-5671(14)00934-4

Proudlove, N. C., Gordon, K., \& Boaden, R. (2003). Can good bed management solve the overcrowding in accident and emergency departments ? Emergency Medicine Journal, 20, 149-156.

Quarantelli, E. L., \& Perry, R. W. (2005). A social science research agenda for the disasters of the 21 st century: theoretical, methodological, and empirical issues and their professional implementation. What Is a Disaster? New Answers to Old Questions, 325-396.

Ranjan, E. S., \& Abenayake, C. C. (2014). A Study on Community's Perception on Disaster Resilience Concept. Procedia Economics and Finance, 18, 88-94. doi:10.1016/S2212-5671(14)00917-4

Rockenschaub, G., \& Harbou, K. V. (2013). Disaster resilient hospitals: An essential for all-hazards emergency preparedness. World Hospitals and Health Services Journal of the International Hospital Federation Papers from the 38th IHF World Hospital Congress in Oslo, 49(4), 28-30. 
Rose, A., \& Liao, S.-Y. (2005). Modeling Regional Economic Resilience to Disasters: A Computable General Equilibrium Analysis of Water Service Disruptions. Journal of Regional Science, 45(1), 75-112.

Samsuddin, N. M., Takim, R., Nawawi, A. H., \& Esa, M. R. (2015). Critical Components Contributing to Disaster Resilience Hospitals. Australian Journal of Basic and Applied Sciences, 9(7), 72-75.

Seguí-Mas, E., \& Izquierdo, R. J. S. (2009). Studying the financial resources for agri-food industry and rural development: Description of human capital in credit unions through delphi analysis. Interciencia, 34(10), 718-724.

Smith, S. M., Gorski, J., \& Vennelakanti, H. C. (2010). Disaster preparedness and response : a challenge for hospitals in earthquake-prone countries. International Journal Emergency Management.

Subramaniam, S. (2013). Government springs into action following hospital ceiling collapse. In Press Conference Monday, September 30, 2013, Kuala Lumpur. Astro Awani.

Subramaniam, S. (2014a). Filth, neglect at hospitals spark uproar. In Press Conference Friday, January 10, 2014, Petaling Jaya. The Malay Mail.

Subramaniam, S. (2014b). Fire at KL Hospital control room. In Press Conference Thursday, February 6, 2014, Kuala Lumpur. The Sun Daily.

Subramaniam, S. (2014c). Hospital fire under probe. In Press Conference Sunday, January 13, 2014, Petaling Jaya. The Sun Daily.

Susil, J. (2013). Hospital fire causes malfunction to radiology equipment. In Press Conference Thursday, March 27, 2013, Kuching. Borneo Post.

Takim, R., Mohamed-Shaari, S., \& Mohd-Nordin, R. (2013). Transparency Initiative (TI) for Enhancing Quality of Life: Behavioural Components that Lead to Corruption in Construction. Procedia - Social and Behavioral Sciences, 101, 110-119. doi:10.1016/j.sbspro.2013.07.184

United Nations International Strategy for Disaster Reduction (UNISDR). (2007). Terminology: basic terms of disaster risk reduction.

Voogd, H. (2004). Disaster prevention in urban environment. European Journal of Spatial Development, 12, 1-14.

Yahaya, H. (2015). Hospitals and clinics destroyed in floods estimated at RM281 mil. In Press Conference, Saturday, January 10, 2015, Butterworth. Astro Awani.

Yusof, F. (2014). Negligence May Be Root Cause of Fire, Death at Sarawak Hospital. In Press Conference Sunday, February, 16 2014, Sarawak General Hospital.

Zhong, S., Hou, X.-Y., Clark, M., Zhang, Y.-L., Wang, L., Xu, L.-Z., \& Fitzgerald, G. (2014). Diasaster Resilience in tertiary hospitals: a cross sectional survey in Shandong Province, China. BMC Health Services Research, (14), 135-144. 